Results Previous suicidal attempts were present in 29 (9.7\%) among which six have attempted more than twice. Majority $(25,86.2 \%)$ were deliberate self-poisoning (DSP) while few were intentional self harm $(4,13.8 \%)$. Knowledge of family or close friend who committed suicide was reported by 96 $(32 \%)$. There were $13(4.4 \%)$ reported suicides in biological family while 46 (15.4\%) were close friends and 42 (14\%) were neighbours. Among the known persons of DSP, drugs were consumed by 30 (43.5\%) and pesticides by 26 (37.7\%). Among intentional self harm the commonest method used was fire $(11,45.8 \%)$ and hanging/strangulation $(07,29.2 \%)$. The time lapse between the index suicidal attempt in the subjects was within 1 year of the suicidal attempt of the family member or friend in 45 (41.3\%) of those who reported knowledge of a family member or close friend who committed suicide.

Conclusion The number with past suicidal attempts in our study is $10 \%$ which is a contrast to $54 \%$ reporting a previous suicide attempt in the WHO/EU multi-centre study on parasuicide. A total of $33 \%$ reporting knowledge of a close friend relative or neighbour who attempted suicide may indicate a strong influence of models in suicidal behaviour.

\title{
0218 SUICIDAL BEHAVIOUR AMONG THOSE WHO ATTEMPTED SUICIDE AND THEIR CLOSE RELATIVES/FRIENDS
}

P de Silva*, D de Silva, S Jayasinghe, R de Alwis Seneviratne, M Abeyratne, D Rajapakse, N Mendis Correspondence: Ministry of Health, 18/3 Wijesekara Road, Dehiwala 001, Sri Lanka

10.1136/ip.2010.029215.218

Objectives To describe the repetition of suicidal attempts and the awareness of suicidal behaviour among close people.

Methods From 668 attempted suicides presented to National Hospital of Sri Lanka (April to December 2002), 300 were randomly selected and interviewed. 